\title{
Determinants of Project Sustainability: The Case of NGO Projects in West Arsi Zone
}

\author{
Abdurahiman Haji Hamda, Matewos Kebede* \\ Department of Accounting and Finance, Jimma University, Jimma, Ethiopia \\ Email address: \\ Sabaif2012@gmail.com (A. H. Hamda), krmatewos@gmail.com (M. Kebede) \\ ${ }^{*}$ Corresponding author
}

\section{To cite this article:}

Abdurahiman Haji Hamda, Matewos Kebede. Determinants of Project Sustainability: The Case of NGO Projects in West Arsi Zone. European Business \& Management. Vol. 7, No. 4, 2021, pp. 95-104. doi: 10.11648/j.ebm.20210704.11

Received: March 5, 2021; Accepted: June 23, 2021; Published: July 10, 2021

\begin{abstract}
This study analyses the sustainability of Non-Governmental Organization implemented projects phased out since 2015. The objective of this study is to assess determinants of projects sustainability in West Arsi Zone, Ethiopia. In order to achieve this objective, descriptive analysis and econometric model were carried out. The study employed both primary and secondary data sources. Primary data was collected from sample target beneficiaries using structured questionnaire whereas the secondary data was collected from published and unpublished sources. The target population was 11,626 beneficiaries addressed by Non-Governmental Organizations implemented that get phase out in the past five years (2014-2019) out of which 240 sample respondents were drawn based on probability proportion to sample. Descriptive analysis was used to describe the socio-economic and demographic characteristics of sample project beneficiaries. Key informant interview was done using two person per each project sampled for the study with a composition of officer and focal person from line project signatory offices. To draw conclusion about population under the study, different tests were undertaken for critical assumption of statistical analysis. The result of tests for assumptions between variables shows that the data is adequate to run regressions. From the result of the study, educational level of Non-Governmental Organizations implemented project beneficiaries, community contribution (money, labor, and local materials, price/cost of project inputs, government involvement and follow up in project after phase out of donors, complementing effort from government and execution of planned exit strategies throughout the whole project life are variables that influence sustainability of projects implemented by Non-Governmental Organizations. It can be recommended that more effective project sustainability results can be achieved through execution of planned project exit strategies throughout the whole project life. Moreover, the finding of the study encourage government to endeavor design and in place of exit strategies, follow up its execution and ensure accountability system if any failure could happen.
\end{abstract}

Keywords: Project, Sustainability, NGO, Beneficiaries, Probit, Marginal Effect

\section{Introduction}

\subsection{Background of the Study}

Non-Government Organizations (NGOs) both local and international non-profit organizations primarily engaged in development activities, relief, and rehabilitation work. They are recognized as very important institutions in development. Globally, NGOs are considered as the third sector that plays a great role in the gap between supply made by private and government sectors. NGOs engage in various areas such as relief and humanitarian aid, disaster risk management, conflict resolution, environmental protection, and poverty alleviation, among others. Many NGOs endeavour to deliver basic services to people in need and organizing policy advocacy and public campaigns for change [18].

NGOs employee project management approaches to deploy specific amount of donor provided resources to address typical socio-economic problems in a targeted community within a specific time frame and budget constraint. The core principle in NGO lead project management is ensuring project outcome sustainability. Success in the management of NGO project; hence, measured by the extent at which the project management capacitate targeted beneficiaries and relevant stakeholders in ensuring sustainability of project outcomes after major 
assistance from donor is completed.

Bennett stated the term "Sustainable" means to endure, to last, and to keep in being. The two terms used interchangeably together; Sustainable development would be all about marshalling resources to ensure that some measure of human well-being is sustained over time [3]. Organization of Economic Cooperation and Development (OECD) presents three dimensions of project sustainability: 1) continuation of positive benefits resulted from the project practices, 2) probability that these benefits and achieved institutional structures will be maintained and 3) the ability to be resistant to risks, both internal and external [2].

Empirical studies on sustainability of donor funded project, albeit limited, identified several instances of failure in ensuring project sustainability which suggests the need for further studies to identify the factors associated with donor funded projects sustainability. According to the information from the District Executive Director's office, more than two hundred (200) government and donor funded projects have been initiated in Iringa District [16]. Despite this heavy investment in clean water projects, still water shortage problem is high at Iringa District due to gaps in projects sustainability. Another study by Obasanjo pointed out analysis of the capital economic structure have identified the complexity of getting resources to the people, getting people to participate, financing and managing delivery of services at micro and macro levels as major challenges for projects sustainability [25]. Unsurprisingly, poor communities have continued to witness a decline in living standards, increasing levels of poverty and deterioration in infrastructures.

Sustainability cannot be achieved without stakeholder involvement and support. Stakeholders should actively participate to influence the direction and detail of design and implementation of the projects. Allocating adequate time and resources for participatory analysis and responding to demand-led approaches are important ways to improve participation [24].

Traditions, core values and customs within the community are part of the socio-cultural factor and since they steer the behaviour of the community members, they have significant effects on the project success and sustainability. Furthermore, the basic living standards in the area, the level and availability of services and technology and environmental conditions have effects on the project and its sustainability [13].

Abdulahi identified four main factors that play to influence project sustainability such as community participation, community capacity building, project leadership and monitoring and evaluation of project [1]. Judging whether a project and its benefits are sustainable is important as a means of determining project success. However, the studies ignored other important factors affecting donor funded projects pertaining to government strategies, socio-economic factors, and target community participation. Therefore, understanding what factors influence sustainability is even more important for designing better projects in the future.

\subsection{Statement of the Problem}

Both international and national NGOs play an important role in development throughout the developing country. They offer services national governments are unable to provide for their citizens [10]. However, different scholars studied factors affecting sustainability of project outcomes. To mention few, Esther Mukoya Mutimba who studied determinants of sustainability of selected donor funded projects in Ganze constituency in Kenya revealed a strong positive correlation between management practices and sustainability in projects thus reflecting that project with good management practices had higher chance of sustainability [8]. Jimson Joseph Chumbula studied the sustainability of water projects in Tanzania [17]. The result of the study revealed that project maintenance per annum and meetings with community conducted per annum were found to affect sustainability of the project.

The Ethiopian government in collaboration with different partners have accorded high priority to the poverty reduction sectors and have shown commitment to design, generate funds and support implementation of different projects. Despite the recognition of the contribution of NGOs implemented projects, very limited studies have been made on sustainability of donor funded projects. As part of this effort, several projects have been designed and implemented and some are under implementation in West Arsi zone since the establishment of the zone. Although efforts have been made since then, there are problems in continuously generating benefits as targeted.

One of the critical problems concerning the projects implemented by NGOs in West Arsi Zone is sustainability that occurs after project phase-out. In this regard, although they are expected to continue as per the project plan or agreement signed between donor and government/community, significant number of projects failed to continue after project completion [30]. To improve this situation, it is necessary to identify key exit strategies design and implementations adapted and assess the extent of target community involvement and government strategies in influencing project sustainability. However, none attempted to investigate sustainability of non-governmental organizations implemented projects and no research has been done within the aforementioned geographical area to investigate factors affecting sustainability of donor funded projects. Therefore, this study attempted to seek answer for what are the main factors affecting sustainability of donor funded projects implemented in West Arsi Zone. The study findings helpfully provide the ways forward that will help the government and the concerned community to arrive at the desired targets; also, it will be used by the local government of the zone to refine the approaches that have been used for quite a long time in initiating sustainability.

The general objective of the study is to assess the determinants of projects sustainability implemented by NGOs in West Arsi Zone, Ethiopia. The specific objectives of the study are: to describe the socio economic and 
demographic characteristics of projects beneficiaries in the study area; assess the extent to which government strategies determine sustainability of donor projects; assess the design and implementation of key exit strategies adapted for ensuring project sustainability; examine how target community involvement at different stages of project management cycle influences the sustainability, and identify factors affecting projects sustainability of the beneficiaries in the study area.

\section{Review of Related Literature}

\subsection{Theoretical Literature Review}

In Ethiopia, there are different forms of NGOs and the main types are "Local Organization" means a civil society organization formed under the laws of Ethiopia by Ethiopians, foreigners resident in Ethiopia or both; "Foreign Organization" means a non-governmental organization formed under the laws of foreign countries and registered to operate in Ethiopia; "Charitable Organization" means an organization established with the aim of working for the interest of general public or third party; "Consortium" means a grouping formed by two or more civil societies Organizations, and includes consortia of consortiums [22].

Evolution of NGOs begun back in the 1910s, in Ethiopia, but they were few. Until 1973/74 there were about 18 registered NGOs. Due to the 1984/85 drought of Ethiopia their number increased to 58. As of April 2002, the number reached to 429 . According to the registry of Ministry of Justice in addition to the federal-level, regions, too, have registered many more localized NGOs, and if included the total number of legally registered $\mathrm{CSO} / \mathrm{NGOs}$ would be more than 3,000 [22].

Clark said that through strategic use of their grass roots experience, NGOs can make an invaluable contribution to development understanding [5]. According to Rahmato et al the heavy influx of foreign INGOs at the height of the famine crisis and the emergency food assistance they brought with them in Ethiopia during the Derg regime not only helped stave off the crisis but also provided a foundation for the growing involvement of INGOs in the country [27].

There are many definitions of sustainability and even more interpretation of its meanings. These are terms which are used frequently in development discourse and can be sources of misunderstanding or misrepresentation. In the most obvious sense, the term "sustainable" refers to something which can be sustained or kept going. But it also refers to resource use and lifestyles which do not damage resources or society [21].

Sustainability is of the opinion that the long-term sustainability of micro projects not only depends on community's active participation in selecting technical options and services, but also end users need to make some responsibility for cost sharing and investment support [28]. The IFAD Strategic Framework 2007-2010 defines sustainability as ensuring that the institutions supported through projects and the benefits realized are maintained and continue after the end of the project [14].

\subsection{Empirical Literature}

Sustainability of the project is dependent on the performance of institutions. Project sustainability is indicated by the ability to continue to meet objectives defined in tern of benefit levels. Clarke P. and Oswald K. adds that projects produce specific benefits for targeted beneficiaries which ideally should continue to increase after project completion [6]. More narrowly, one can speak of sustaining or keeping in operation a particular WS\&S facility, such as a sewer system or hand pump.

When communities recover from costs or stabilize in raising funds for maintenance, it contributes to sustainability by increasing resources and expanding benefits. Beneficiary contribution to capital costs, either labor or money, may be a significant indicator of system sustainability. However, a willingness to contribute to capital expenditures, in cash or in-kind, does not on itself ensure sustainability [7].

Participation is defined as a process through which stakeholders influence and share control over development initiatives, and the decisions and resources which affect them [31]. Community participation in a micro project means the contribution of the people in the area of micro project in identifying, characterizing the problem and implementation [26].

In the views of Levinger et al, a well designed and implemented exit strategy bear six elements, namely: (i) Planning for exit from the beginning; (ii) Developing partnership and local linkages; (iii) Building local organizational and human capacities; (iv) Mobilizing local and external resources; (v) Staggering the phasing of activities and resources; and (vi) Allowing roles and relationship to evolve [20]. Based on the above examined background, exit strategies design and implementation adapted to ensure sustainability of donor funded projects in the study area was of the focus of this study.

\section{Research Methodology}

\subsection{Method of Data Collection and Sampling}

In order to select a representative sample of actors multistage random sampling techniques were implemented. In the first stage, out of the 13 woredas and 4 towns in the zone, three woredas namely Negelle Arsi, Siraro and Shashamane where significant number of NGOs with agriculture and related sectors of interventions were found in a mixed composition (local those established under Ethiopian organizations of civil societies proclamation or internationally formed under the laws of foreign countries), since 2015, were identified and selected purposively based on secondary data collected from West Arsi zone Finance and Economic Cooperation office. In the second stage, from target 30 projects implemented by NGOs in the three woredas, seven that accounts about $30 \%$ of the total phased 
out projects were selected using probability proportional to sample size. This was based on heterogeneity of projects and [23] recommendation that when the target population is small (less than 1000 members), a sample of about $30 \%$ is adequate for research. This was undertaken after exhaustively listing projects taking into consideration 20 of the level of heterogeneity of the projects in terms of area of intervention (among agriculture related sectors) and, money and time required to collect data from these entire projects or contacts and considering.

Finally, in the third stage, the sample clients/beneficiaries of the projects were selected using simple random sampling techniques where each and all members of the project beneficiaries have equal chance of being selected as respondent. This was undertaken after having sampled project document so as to manage gaps in sampling exact number of sampled woreda and project specific target communities benefited from projects designed for more than one woredas. The approach used for this study to determine the sample size from the targeted population of clients/beneficiaries, project managers/officers, and selected project partner office experts was adopted from [19] as illustrated below:

$$
n=\frac{z^{2} \cdot p \cdot q \cdot N}{e^{2} N-1+z^{2} \cdot p \cdot q}
$$

Where: $\mathrm{n}$ is the required sample size, $\mathrm{N}$ is the population size, $\mathrm{z}$ is value of standard variate at a given confidence level, $\mathrm{p}$ is sample population, is $\mathrm{q}$ is (1-p), and e is acceptable error.

A total of 14 individuals from project partners (project signatory offices), two per each project sampled for the study with a composition of officer and focal person from line project signatory offices were selected for interview. Furthermore, two experts working in zone NGOs coordination department were selected.

\subsection{Data Processing and Analysis}

This study was employed both qualitative and quantitative data. Data management such as data coding, entry and editing/checking was done using SPSS software whereas data analysis such as descriptive, inferential, and econometric model were done using STATA (Version 14). Probit regression model was employed to determine the factors affecting sustainability of the projects. The model was necessary to explain the prediction of factors likely to determine an outcome variable (sustainability) which is based on a set of values and the sustainability was dichotomous variable with two values, where it takes value $=1$ if the projects were perceived to be sustainable and 0 otherwise.

The probit model is built on a latent variable with the following formulation [32].

$$
\mathrm{Yi} *=\beta \mathrm{iXi}+\text { uiui } \sim \mathrm{N}(0,1)
$$

$$
\mathrm{Y}=1 \text { if } \mathrm{Y}^{* \mathrm{i}}>0, \mathrm{Y}=0 \text { if } \mathrm{Y}^{*} \mathrm{I}<=0
$$

Where:

$\mathrm{Yi}^{*}$ is a latent (unobservable) variable representing whether the project outcome is sustained or not. $\mathrm{Xi}$ is a vector of independent variables hypothesized to affect projects sustainability, $\beta \mathrm{i}=\mathrm{is}$ a vector of parameters to be estimated which measures the effects of explanatory variables on sustainability of projects, $u_{i}$ is normally distributed disturbance with mean $(0)$ and constant variance and captures all unmeasured variables $\mathrm{Y}=\mathrm{is}$ a dependent variable which takes value of 1 if the project outcome is sustainable and 0 otherwise.

The qualitative data was collected from the various composition of respondents was also analyzed along with document review and were discussed with quantitative data as deemed necessary.

Table 1. Description of the dependent and independent variables used in the model.

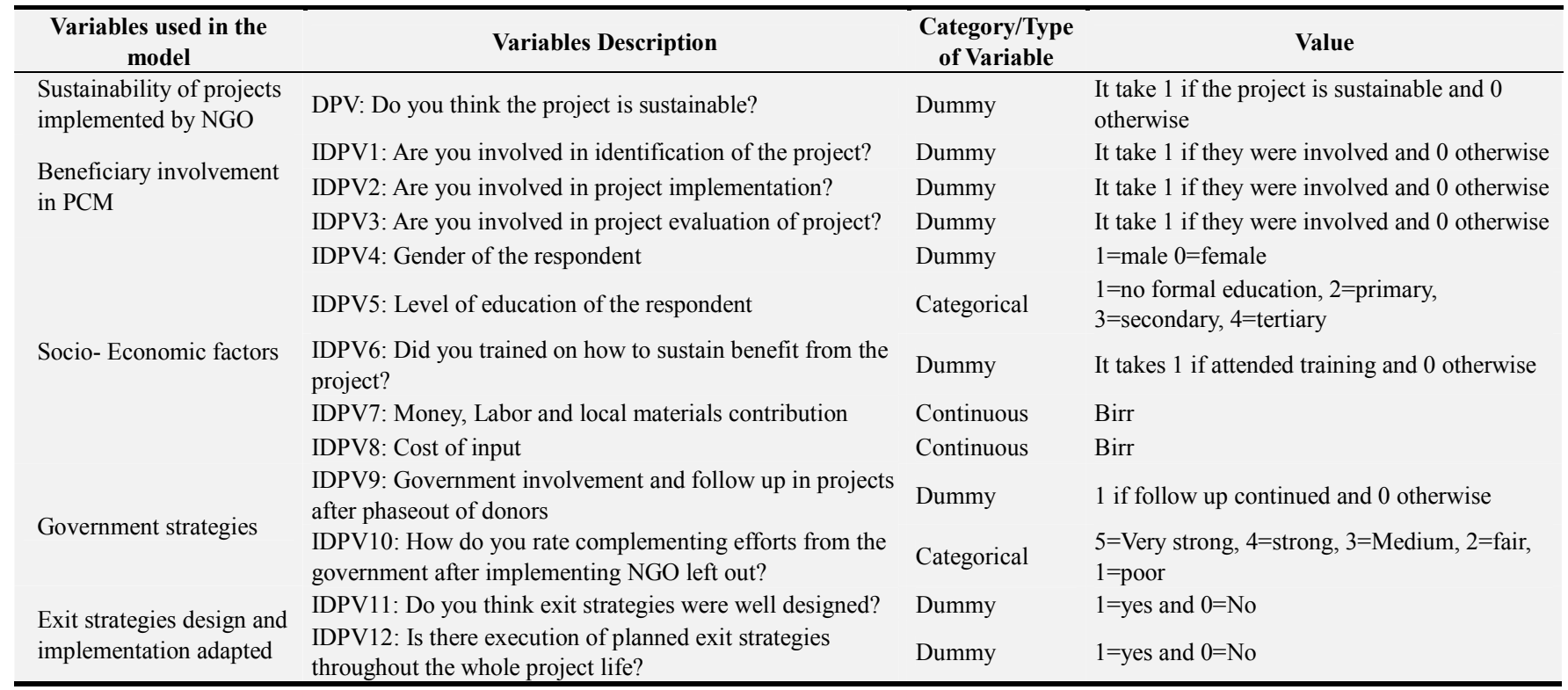




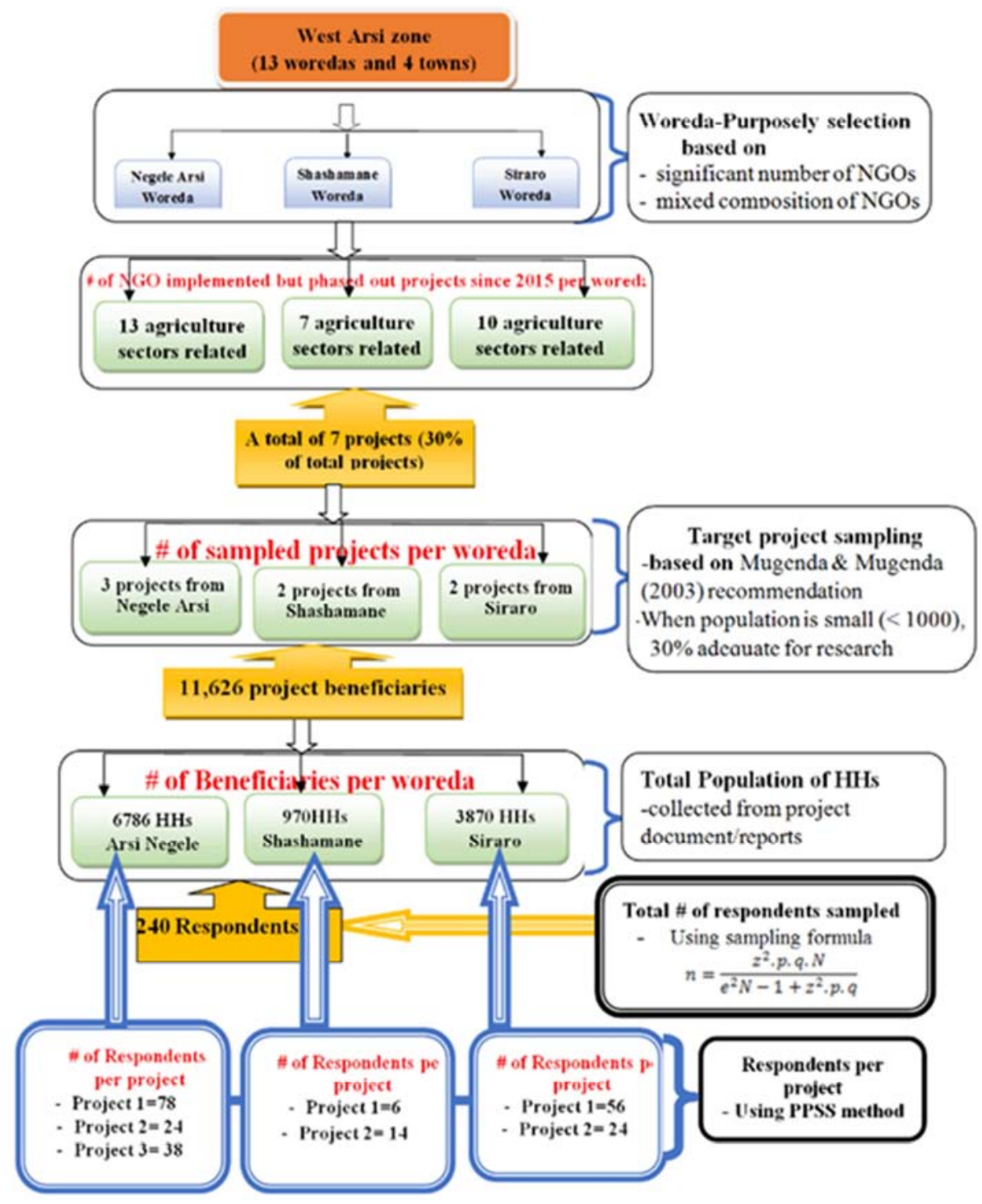

Figure 1. Summary of overall project beneficiary sampling procedure.

\section{Results and Discussions}

\subsection{Socio-economic and Demographic Characteristics of the Respondents}

The study finding shows clearly that 60.8 and 20 percent of the sample project beneficiary respondents were within the age brackets of 35-45 and 46-55 years, respectively. Whereas those respondents who were older than 55 and younger than 35 years represented about 19.2 percent of the sampled project target beneficiaries. This implies that most of the NGOs implemented project target clients were young who are in the productive age group. This is due to the fact that NGOs working in agriculture and agriculture related sectors gave more focus to enhancing production and productivity which in turn resulted in poverty reduction than service and emergency responses.

The gender of the respondents, the females account $26.6 \%$ of the total of NGOs implemented project beneficiaries and the remaining $73.4 \%$ are male beneficiaries.

With regards to the marital status of the participants, most of them were married that accounts $79.6 \%$ (191) of the total respondents. On the other hand, about $10.4 \%$ (25) of the participants were not married/single. Most of the aged and experienced employees leave the bureau and fresh university graduates join it, implying the bureau could not retain its experienced employees.

\subsection{Educational Level of Respondents}

Further analysis however revealed that majority of the respondents $(50.5 \%)$ had no formal education out of which $13.8 \%$ are females. It was also realized that those respondents who attended primary and secondary school constitutes $38 \%$ and $11.7 \%$ respectively (Figure 2). The analysis of the study findings is an indicative of the act that majority of the respondents had no formal education and could have a challenge to understand the matter under review and thus difficult to articulate project sustainability issues very well. 


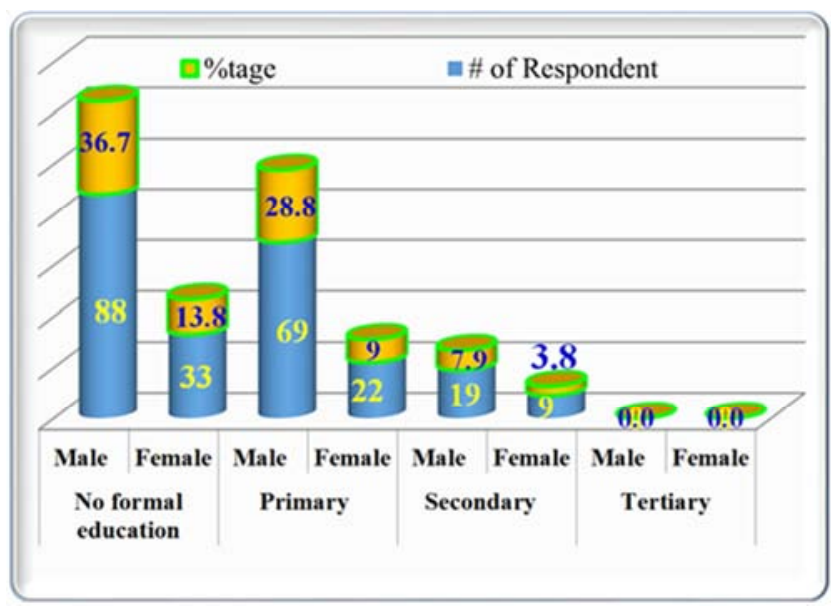

Sources: Survey result, 2020

Figure 2. Sex disaggregated educational distribution of the respondents.

\subsection{Respondents Economic Occupation and Capability}

The major economic occupations practiced in the study area were mixed farming and livestock herding followed by crop production. The survey results indicate that about $67 \%$, $23 \%$ and $7 \%$ of the respondents had participated in mixed farming, livestock herding and crop production activities, respectively (Figure 3). This reflected that serious attention should be given to protect the problem of tree destruction in the area.

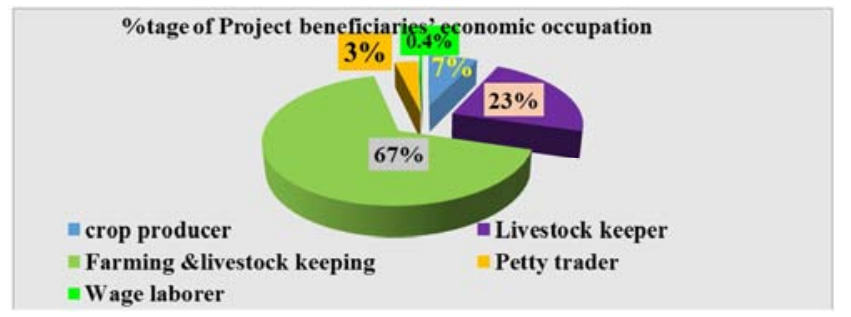

Sources: Survey result, 2020

Figure 3. Respondents distribution in economic occupation.

According to the results shown in Table 2, 72.08 percent of the respondents were not capable to contribute the required monetary and/or in-kind contribution to sustain project outcome.

Table 2. Economic capability of Respondents.

\begin{tabular}{lll}
\hline $\begin{array}{l}\text { Are you capable to contribute monetary } \\
\text { and/or in kind contribution required for } \\
\text { project sustainability }\end{array}$ & Frequency & Percent \\
\hline yes & 67 & 27.92 \\
No & 173 & 72.08 \\
Total & 240 & 100 \\
\hline
\end{tabular}

Sources: survey result, 2020

\subsection{Influence of Government Strategies on Project Sustainability}

Sampled beneficiaries of the projects selected for the study were asked to indicate the extent to which complementing effort from government and its involvement and follow up of donor funded projects after phase out determines sustainability of projects implemented by NGOs. They were given five Likert-scale points ranging from very strong to poor which they were to choose from. The study revealed that most respondents were in agreement that government involvement and follow up of donor funded projects after phase out of implementing organization greatly influences the sustainability of the projects. It also indicates that majority of the respondent $(60.8 \%)$ scored that government involvement and follow up after phase-out of implementing organization influences the sustainability of donor funded projects very strongly (Figure 4).

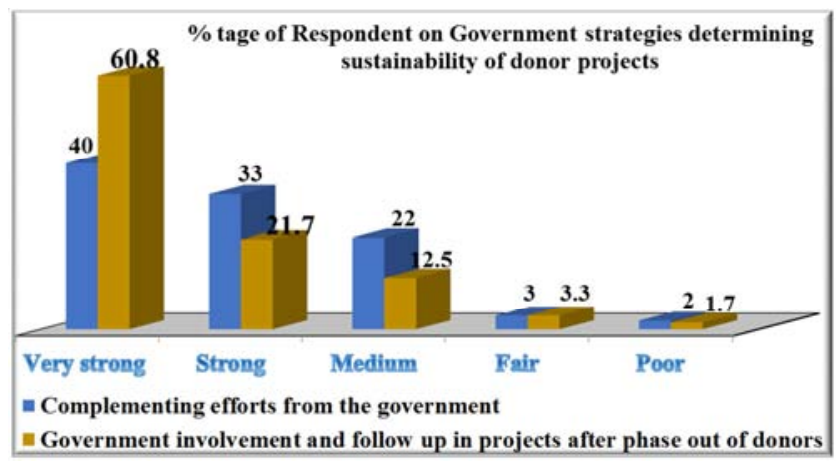

Sources: survey result, 2020

Figure 4. Beneficiary Rates on Government strategy influence of project sustainability.

Figure 4 sought to establish the extent at which complementing effort from government influence sustainability of projects when implementing organization pull out. The result found that 40,33 and 22 percent of the respondents scored complementing effort from government influence sustainability of projects to a very strong, strong and medium extent respectively. This result agrees with finding from project partner sector experts and project coordinators that monitoring project outcome after phase out of implementation by NGOs has significant influence on sustainability of the project results.

Participants from the project signatory offices were asked to rate to what extent government strategy influences project sustainability. It was also found that 71.4 percent of the experts from project signatory offices had rated very strong that complementing efforts from the government influences sustainability of projects implemented by NGOs while the remaining 21.4 and 7.2 percent rated influence of complementing efforts from the government on project sustainability as strong and medium respectively.

With regard the effect of government involvement and follow up in projects after phase out of donors on sustainability of projects, the study revealed that 50 percent of experts rated very strong influence of government involvement and follow up in projects on sustainability. 


\subsection{Extent of Community Involvement Influence on Project Sustainability}

The study showed that majority of the respondents $(90.4 \%)$ rated their degree of involvement in project implementation influences on the project sustainability as very strong. Also, more than 73 percent of the effect of project beneficiary participation in project identification on such a project implemented by NGOs was rated as very strong and strong (Figure 5). The findings are in line with Holland study who confirmed the findings when he concluded that community engagement the collaboration between institutions and governments (local, state, national, global) for the mutually benefit of exchange of resources and knowledge in a partnership and reciprocity context in the US and hence influence sustainability [12].

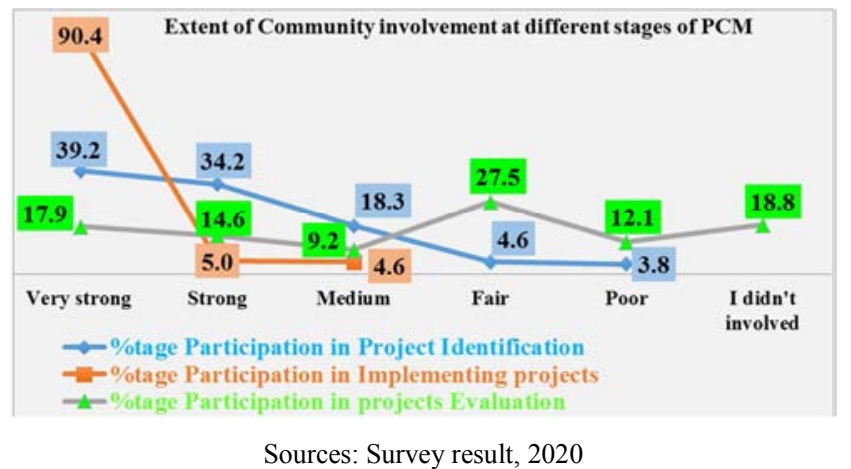

Figure 5. Extent of Community involvement in PCM.

The findings further showed that majority of the respondents agreed that community engagement in project evaluation plays a key role in enhancing the sustainability of NGOs implemented projects. This was supported by majority of the respondents $(70 \%)$ who strongly agreed that their participation in project evaluation influences project sustainability to a reasonable or more extent. The findings complement that of [7] who reported that Monitoring and Evaluation should involve beneficiaries, giving them the opportunity to decide on the criteria of success. Evaluations should be used as a management tool to identify any deficiencies and develop an action plan for sustainability.

\subsection{Design and Implementation of Exit Strategies Adapted for Ensuring Project Sustainability}

To assess the design and implementation of key exit strategies adapted for ensuring project sustainability; respondents were asked to point out design and implementation of key exit strategies in place. A total of Six (6) exit strategies were used in collecting information on respondents' weight with regard to the level (low, medium, high) of exit strategies execution throughout the project life and how key each strategy was in ensuring project sustainability.

The result indicates appropriate execution of the project activities and resources, beneficiaries' involvement in PCM and ensuring responsibilities and essence of the project to the community and relevant partners are of key project exit strategies designed and in place. With exception of two project exit strategies (planning for exit and execution of the plan and partnership and local linkages) which significant number of the respondents scored its execution throughout the whole project life at low level, more than $50 \%$ of the respondents weighted the remaining exit strategies designed and in place for the projects under study at high levels. The result implies that sustainability of NGOs implemented projects does not take the two project exit strategies into high level of consideration.

\subsection{Factors Affecting Sustainability of Projects Implemented by NGOs}

Probit regression model was employed to determine factors affecting the sustainability of projects implemented by NGOs.

According to Field to run a linear regression, checking critical assumptions is essential and it is helpful to draw conclusion about the population under study [9]. In this regard, normality of the residual variables, homoscedasticity and multi collinearity between variables were checked as follows:

\subsubsection{Standardized (Z) Score Value}

Before proceeding in to the other testes the researcher checked for the outliers. Checking for standardized (Z) scores for absolute higher values greater than 3.29 is important to insure the normality. As the following chart indicates all the values of $\mathrm{Z}$ score is found to be absolute higher values of greater than 3 .

\subsubsection{Homoscedasticity}

Homoscedasticity is the extent to which the data values for the dependent and independent variables have equal variances [9]. At each level of the predictor variables, the variance of the residual terms should be constant. This just means that the residuals at each level of the predictors should have the same variance, therefore checking for this assumption is helpful for the fitness of the regression model. Accordingly, robust method was used to correct the possible problem of heteroscedasticity.

\subsubsection{Multi Collinearity}

Before running the model to estimate the equation of Factors Affecting Sustainability of Projects Implemented by NGOs, the association between explanatory variables was checked using variance inflation factor (VIF), which shows how variance of estimate is inflated because of the presence of multicollinearity [11]. VIF is defined as:

$$
\mathrm{VIF}=\frac{1}{1-R^{2}}
$$

Where,

$\mathrm{R}^{2}$ is the value of coefficient of multiple determinations

According to Saunders et al, most regression programs can compute variance inflation factors (VIF) for each variable and as a rule of thumb; VIF above 5.0 suggests problems 
with multi collinearity [29]. Field, also underline that, values for "Tolerance" below 0.1 indicate serious problems, although several statisticians suggest that values for "Tolerance" below 0.2 are worthy of concern [9]. Accordingly, multicollinearity test was presented in table 3, which indicates there is no problem of multicollinearity in this model, because VIF (variance inflation factor) of the model is well less than 5.0 and the tolerance is not less than 0.100 . Therefore, the mean VIF is 1.13 that shows variables are not overlapped and they are free from collinearity effect.

Table 3. Test of Multi Collinearity.

\begin{tabular}{lll}
\hline Variable & VIF & 1/VIF \\
\hline Resource contr & 1.26 & 0.793682 \\
Training & 1.2 & 0.834951 \\
rate_gov't comp effort & 1.17 & 0.851909 \\
Part_evaluat & 1.17 & 0.852385 \\
Sex & 1.13 & 0.885702 \\
Exit_des_inplace & 1.13 & 0.888805 \\
Excut_exit_strat & 1.12 & 0.893141 \\
Educat_HH & 1.11 & 0.903873 \\
Invo_pro_idetif & 1.1 & 0.906657 \\
Cost_proj_input & 1.08 & 0.923417 \\
Part_implement & 1.05 & 0.956014 \\
Gov't invol_followup & 1.03 & 0.966371 \\
Mean VIF & 1.13 & \\
\hline
\end{tabular}

Source: Own Computation, 2020

\subsection{Probit Model Analysis}

Probit Model Result

Table 4. Determinants of the sustainability of project implemented by NGOs: Probit Model Result.

\begin{tabular}{|c|c|c|c|c|c|}
\hline Sustainability & Coef. & Robust Std. Err. & $\mathbf{z}$ & $\mathbf{P}>\mathbf{Z}$ & $d y / d x$ \\
\hline Involvement in project identification & $0.833 * * *$ & 0.255 & 3.26 & 0.001 & 0.2233 \\
\hline Participation in project implement & 0.107 & 0.261 & 0.41 & 0.682 & 0.0262 \\
\hline Involvement in project evaluation & 0.185 & 0.249 & 0.74 & 0.458 & 0.0444 \\
\hline Sex of the respondent & -0.258 & 0.326 & -0.79 & 0.429 & -0.5664 \\
\hline Education status of the respondent & $0.152 * * *$ & 0.048 & 3.17 & 0.002 & 0.0362 \\
\hline Training & 0.177 & 0.276 & 0.64 & 0.523 & 0.0433 \\
\hline Resource contribution & $-0.007 * * *$ & 0.001 & -7.08 & 0.000 & -0.0018 \\
\hline Gov involvement and follow up & $0.891 * * *$ & 0.244 & 3.66 & 0.000 & 0.2061 \\
\hline Rate of complementing effort gov't & $-0.997 * * *$ & 0.216 & -4.62 & 0.000 & -0.1250 \\
\hline Exit strategy design in place & 0.119 & 0.268 & 0.45 & 0.656 & 0.0281 \\
\hline Execution of planned exit strategy & $0.491 * *$ & 0.240 & 2.04 & 0.041 & 0.2380 \\
\hline cons & 4.666 & 0.942 & 4.96 & 0.000 & \\
\hline
\end{tabular}

Number of obs $=240$, Wald chi2 $(12)=102.89$, Prob $>$ chi $2=0.0000$

Log pseudolikelihood $=-73.175486$ Pseudo $\mathrm{R} 2=0.4885$

$* * *=1 \%, * *=5 \%$ and $*=10 \%$ significance level

The results of probit model chi-square tests applying appropriate degrees of freedom indicate that the overall goodness of fit of the model was statistically significant at a probability of less than $1 \%$. Second, Pseudo $R^{2}$ values indicate that the independent variables included in the regression explain $48.85 \%$ of the variations in the likelihood to sustainable project implemented by NGOs.

The regression results show that there are seven variables that found to be significantly explaining the continuity of benefits after funding cycle (Table 4). These variables are:

1) Project beneficiary involvement in project identification influences

2) Money, labor and local materials contribution

3) Prices/cost of project inputs

4) Execution of planned exit strategies throughout the whole project life
5) Complementing efforts from the government

6) Government involvement and follow up in projects after phase out of donors

7) Education

The Regression model summary depicts the relationship between dependent and independent variables.

Target beneficiary involvement in the project identification stage of PCM was found to have significant and positive influence on sustainability of projects implemented by NGOs at $1 \%$ significance level. The result shows that being participation of target project beneficiaries in project identification stage would increases the probability of NGOs implemented project sustainability by $22.33 \%$ as compared to non-participants. Respondents justified that including them actively in the project identification was mentioned being an efficient factor in enhancing benefit from the project that in 
turn ensures its sustainability. This corroborates with Carol and IFAD findings that community participation levels and their outcomes may manifest differently at different stages of project cycle management depending on the capacity [4] and [15].

From the analysis in the table above, among socio-economic factors included in the model education, resource contribution (money, labor and local materials) and cost of project inputs were found to have significant influence on sustainability of projects implemented by NGOs. These variables are statistically significant at $1 \%$ significance level. Education was found to have positive influences that indicate being in better education category would increases the probability of project sustainability by 3.6 percent. Beneficiaries' resource contribution and change in cost of inputs affects the probability of NGOs implemented project sustainability negatively. A change in resource contribution and cost of inputs would decrease the probability of project sustainability by $0.018 \%$ and $4.5 \%$ respectively. The study thus agrees with UNDP (1997) who noted that project sustainability is heavily dependent of the capacity of the community to continue making use of available resources to maintain project benefits.

Government strategy proxy variables were found to have significant influences on sustainability of projects implemented by NGOs. Relative to very strong rate by target beneficiaries concerning government complementing efforts after project phase out, being in other category rate of beneficiaries would decreases the probability of project sustainability by $12.5 \%$. Moreover, government involvement and follow up in projects after phase out of implementing organization were found to have a positive effect and increases the probability of project sustainability by $20.6 \%$. These finding imply that complementing efforts from the government that supports NGO implemented projects and government involvement and follow up in projects after phase out of implementing organization are positively related to sustainability of the projects.

Execution of planned project exit strategies throughout the whole project life was also found to have significant and positive influence on NGO implemented projects' sustainability at $1 \%$ significance level. It implies that implementation of planned project exit strategy would increases the probability of sustainability of NGO implemented projects by $23.8 \%$.

\section{Conclusions}

It can be concluded from the finding pertaining to project beneficiaries' participation in identification, implementation, and evaluation stages of the PCM that including target beneficiaries of the project actively and acknowledging their opinions and suggestions in the project identification ensures its sustainability.

The study found out that $75.8 \%$ of the respondents rated the level of partnership and local linkages to CBO, Gov't sectors, NGOs etc in ensuring project sustainability beyond its lifespan of the as high. This concludes that NGOs implemented project sustainability is not only about beneficiary but also its partnership and linkage to the partner, CBOs, other NGOs that matters. So, this key project exit strategy is all-important.

From what study pointed out regarding the influences of government strategies on project sustainability, it can be concluded that ensuring government complementing effort and its involvement and follow up in projects after phasing out are vital to ensure project sustainability.

Effort from the government side that complement sustainability of project/s implemented by NGOs, its involvement and follow up in projects after phaseout of implementing organization and execution of planned exit strategies throughout the whole project life were seen to have a positive significant effect on the sustainability of projects implemented by NGOs. Other factors negatively affecting sustainability of donor funded projects were; Prices/cost of project inputs and money, labor and local materials contribution that the project demands from target project beneficiaries.

Since various factors of government strategies, project exit strategies design and implementation adapted and socioeconomic factors affect sustainability of projects implemented by NGOs, project beneficiaries, project managers, supervisors, and projects partners should not stick to only part of some factors. A combination of the various factors will bring significant sustainability NGOs implemented project/s.

\section{Acknowledgements}

Above all, I praise my Allah for being with me whenever I needed him in that not very comfortable part of my life. My thanks also go to my Advisor, Dr. Matwos Kebede, for his comments and, for bearing with my frequent delays in submitting the different parts of this thesis. I am also greatly indebted to my wife, Mariama Abdo, who showed me eternal love and made life easier by motivating me. Really, I do not know what I can do without her. I had such a great time, which will always be in my memory. I owe them a lot for making life more interesting.

\section{References}

[1] Abdulahi A. (2018). Factors influencing the sustainability of donor funded projects in Ethiopia: A case of the camel milk value chain development project in Gursum district. M. A. Thesis. University of Nairobi, Kenya.

[2] ADB (Asian Development Bank), (2010). Special Evaluation Study on Post-Completion Sustainability of Asian Development Bank- Assisted Projects.

[3] Bennett Lynn (2003). "Empowerment and Social Inclusion: A Social Development Perspective on the Cultural and Institutional Foundations of Poverty Reduction. Social Development strategy. Macmillan. New York.

[4] Carol J. De Vita (2001). Building Capacity in Nonprofit Organizations. The Urban Institute-Washington DC-USA. 
[5] Clark J. (1991). Democratizing Development; The Role of Voluntary Organization Earth scans Pub., London.

[6] Clarke P. and Oswald K. (2010). "Why reflect collectively on capacities for change", IDS Bulletin, 41.3, institute of development studies, Brighton.

[7] Elijah Kuria (2016). Assessment of Factors Influencing Sustainability of Donor Funded Projects in Nakuru County, Kenya. M. A. Thesis. Jomo Kenyatta University of Agriculture \& Technology, Kenya.

[8] Esther Mukoya Mutimba (2013). Determinants of Sustainability of Donor Funded Projects: The Case of Selected Projects in Ganze Constituency in Kilifi County, Kenya. M. A. Thesis. University of Nairobi, Kenya.

[9] Field A. (2009) Discovering Statistics Using SPSS. 3rd Edition, Sage Publications Ltd., London.

[10] Gidron, B. Quarles van Ufford, P. \& Bedri Kello, A. (2003). NGOs Dealing with Refugee Resettlement in Ethiopia. NIRP Series 12. Royal Tropical Institute: The Netherlands.

[11] Guajarati, D. N. (1995). Basic Econometrics. Third Edition. McGraw-Hill, New York. USA.

[12] Holland B. (2012). Community engaged scholarship: Your teaching, research and service "Reconsidered." Louisville, KY: University of Louisville.

[13] House S. (2007). How to make Wash Projects Sustainable and Successfully Disengage in Vulnerable Contexts. ACFInternational Network, WASH Service. http://www.actionagainsthunger.org/sites/default/files/publicat ions/Sustainability of WASH projects Guidelines. Pdf.

[14] IFAD, (2007). IFAD Strategic Framework 2007-2010. [http://www.ifad.org/strategic] Site visited on 15/10/2011.

[15] IFAD (2012). Report on IFAD's Development Effectiveness (EB 2012/107/R. 8/Rev. 1). Rome: IFAD.

[16] Iringa District Council (2012). Proportion in Percentage of Rural Water sources in Iringa district; Water Supply and Sanitation Department.

[17] Jimson Joseph Chumbula (2016). Sustainability of Water Projects: A Case if Selected Projects in Iringa District, Tanzania. M. A. Thesis. University of Agriculture, Morogoro, Tanzania.

[18] Karanja G. (2013). Influence of Management Practices on Sustainability of Youth Income Generating Projects: in Murang'a County. International Journal of Education and Research, 2 (2), 1-12.

[19] Kothari, C. R (2004) Research methodology; methods and techniques (2nd revised ed.) New Delhi, New age international (P) Ltd.

[20] Levinger, B and McLeod, J. (2002). Hello, I Must Be Going: Ensuring Quality Services and Sustainable Benefits through Well-Designed Exit Strategies. Education Development Center, Inc. Center for Organizational Learning and Development (COLAD), 55 Chapel Street Newton, MA 02458. $24 \mathrm{pp}$.

[21] Merriam Webster (2010). Online Dictionary. Accessed 2010 May 20.

[22] Ministry of Justice (2015). Database on Associations and Registered. Addis Ababa.

[23] Mugenda, Mugenda (2003). "Research Methods: Quantitative and Qualitative Analysis," Acts Press, Nairobi Kenya.

[24] Nyonje, Kyalo \& Mulwa (2012). Monitoring and Evaluation of Projects and Programs. Nairobi, Kenya: Aura Publishers.

[25] Obasanjo. O (2002): The New Partnership for Africa's Development. Abuja, Nigeria.

[26] Oakley, P. and Marsden, D. (1991). Approaches to Participation in Development International Labour Organization, Geneva. 91pp.

[27] Rahmato D.; Bantirgu A.; \& Endeshaw (2008), CSOs. INGOs in Ethiopia, Partners in Development and Good Governance, A Report Prepared for the Ad Hoc CSO/NGO Task Force, Final Draft, Addis Ababa, retrieved on 3/12/11 from http://www.crdaethiopia.org/Documents/CSOs-

INGOs\%20in\%20Ethiopia\%20Partners\%20in\%20Developme nt.pdf.

[28] Robert A. Boydell (1999). Making rural water supply and sanitation projects sustainable: VOL. 18 NO. 1.

[29] Saunders, M., Lewis, P. \& Thornhill, A. (2009). Research methods for business students (5th edn). Harlow: FT Prentice Hall.

[30] West Arsi zone Finance and Economic Cooperation (2019). NGOs Implemented Projects Assessment Report.

[31] World Bank, (2004). The Returns to Participation in the Nonfarm Sector in Rural Rwanda. Policy Research Working Paper $3462 \quad$ December $2004.2 \mathrm{pp}$ [http://books.google.co.tz/books?id=2VLeWqUaBTo\&pg=PA I\&lpg=PA1\&dq=world + bank $+2004++$ farmers + participation \& source=bl\&ots=] Site visited on 11/7/2013.

[32] Wooldridge, J., 2002. "Inverse Probability Weighted M Estimators for Sample Stratification, Attrition and Stratification," Portuguese Economic Journal, 1, pp. 117-139. 